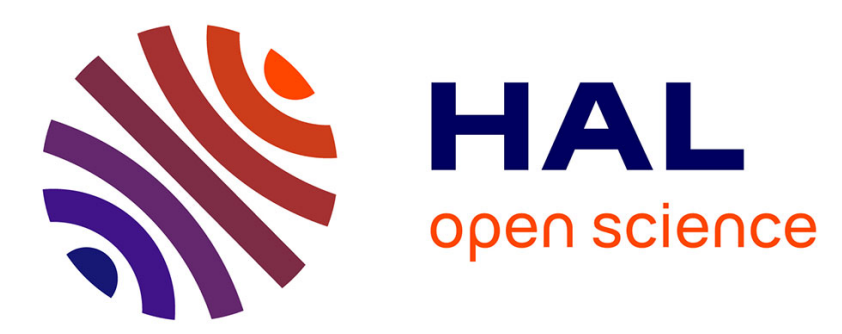

\title{
Ag13-Centered Cuboctahedral Architecture in Inorganic Cluster Chemistry: A DFT Investigation
}

\author{
Samia Kahlal, C. W. Liu, Jean-Yves Saillard
}

\section{To cite this version:}

Samia Kahlal, C. W. Liu, Jean-Yves Saillard. Ag13-Centered Cuboctahedral Architecture in Inorganic Cluster Chemistry: A DFT Investigation. Inorganic Chemistry, 2017, 56 (3), pp.1209-1215. 10.1021/acs.inorgchem.6b02207 . hal-01470477

HAL Id: hal-01470477

\section{https://hal-univ-rennes1.archives-ouvertes.fr/hal-01470477}

Submitted on 27 Mar 2017

HAL is a multi-disciplinary open access archive for the deposit and dissemination of scientific research documents, whether they are published or not. The documents may come from teaching and research institutions in France or abroad, or from public or private research centers.
L'archive ouverte pluridisciplinaire HAL, est destinée au dépôt et à la diffusion de documents scientifiques de niveau recherche, publiés ou non, émanant des établissements d'enseignement et de recherche français ou étrangers, des laboratoires publics ou privés. 


\title{
The Ag13 centered cuboctahedral architecture in inorganic cluster chemistry: A DFT investigation
}

Samia Kahlal, ${ }^{a}$ C. W. Liu, ${ }^{b}$ Jean-Yves Saillard ${ }^{a^{*}}$

a UMR-CNRS, 6226 "Institut des Sciences Chimiques de Rennes"

Université de Rennes 1, 3502 Rennes Cedex (France).

Email : kahlal@univ-rennes1.fr; saillard@univ-rennes1.fr

${ }^{\mathrm{b}}$ Department of Chemistry, National Dong Hwa University, No. 1, Sec. 2, Da Hsueh Rd., Shoufeng, Hualien 97401 (Taiwan, R.O.C.).

E-mail: chenwei@mail.ndhu.edu.tw

\begin{abstract}
The bonding in the $\left[\operatorname{Ag}_{13}\left\{\mu_{3}-\mathrm{Fe}(\mathrm{CO})_{4}\right\}_{8}\right]^{3-/ 5-}$ clusters, which exhibit an $\mathrm{Ag}_{13}$ centered cuboctahedral core, has been analyzed and rationalized by DFT calculations. Not considering the interaction with its encapsulated atom, the empty $\left[\operatorname{Ag}_{12}\left\{\mu_{3}-\mathrm{Fe}(\mathrm{CO})_{4}\right\}_{8}\right]^{4-}$ cage can be considered as the assembly of twelve linearly coordinated 14-electron $\mathrm{Ag}^{\mathrm{I}}$ metal centers. Adding a supplementary $\mathrm{Ag}^{+}$at the center allows some covalent delocalized bonding which to some extent tends to reduce the electron deficiency of the 14-electron centers. Adding now two electrons strengthens the delocalized bonding between the encapsulated atom and its host, making $\left[\mathrm{Ag}_{13}\left\{\mu_{3}-\mathrm{Fe}(\mathrm{CO})_{4}\right\}_{8}\right]^{5-}$ a superatom with two jellium (5s-type) electrons. TDDFT calculations predict near-IR absorption for this penta-anion, because of the presence of an $\mathrm{a}_{1 \mathrm{~g}}$ HOMO in the middle of an energy gap. Luminescence in the same optical range is also suggested. Other related cubococtahedral species, such as $\left[\operatorname{Ag}_{23}(\mathrm{SH})_{16}\right]^{-}$, a model for the known 8-electron $\left[\mathrm{Au}_{23}(\mathrm{SR})_{16}\right]^{-}$species which exhibits a bicapped centered dodecahedral kernel structure, have also been investigated.
\end{abstract}




\section{Introduction}

Within the family of Group 11 metal nanoclusters, the 13-atom centered icosahedral arrangement (Figure 1) is well documented for gold $^{1}$ and has been also reported for silver. ${ }^{2}$ This $\mathrm{M}_{13}$ structure constitutes the kernel of stable mixed-valent closed-shell molecules named superatoms, in which this kernel is protected by an outer shell made of coordinated ligands and, in the case of chalcogenolato ligands, of peripheral $\mathrm{M}^{\mathrm{I}}$ cations. The stability of superatoms is associated with "magic" electron numbers. These "magic" electron counts $(2,8$, $18,20,34 \ldots)$, which are providing closed-shell configurations to $\left[\mathrm{M}_{\mathrm{n}}\right]^{\mathrm{x}+}$ cluster kernels, have been rationalized within a spherical jellium-type model leading to one-electron cluster orbitals somehow resembling the atomic orbitals and ordering as $1 \mathrm{~S}<1 \mathrm{P}<1 \mathrm{D}<2 \mathrm{~S}<1 \mathrm{~F} \ldots{ }^{1 \mathrm{c}}$ The known gold and silver superatoms with centered icosahedral kernels correspond to 8-electron $\left[\mathrm{M}_{13}\right]^{5+}$ species $\left(1 \mathrm{~S}^{2} 1 \mathrm{P}^{6}\right.$ jellium configuration). ${ }^{1,2}$ The $\mathrm{M}$ valence nd electrons are supposed not to be involved significantly in the bonding and the 8 electrons can be considered as provided by the $(n+1) s$ atomic orbitals $(A O s)$. It is noteworthy that a simple Hückel-type calculation on a centered icosahedron considering 13 s-type AOs leads to the formation of four bonding MO's of $a_{l g}$ and $t_{l u}$ irreducible representations (in $I_{h}$ symmetry) which can be identified to the spherical jellium $1 \mathrm{~S}$ and $1 \mathrm{P}$ orbitals, the Hückel $h_{g}$ antibonding LUMOs corresponding to the next $1 \mathrm{D}$ jellium level. Thus, such a structure appears perfectly suited for an 8-electron closed-shell configuration, and cannot afford for larger electron numbers (occupation of antibonding orbitals). A typical 8-electron silver superatom is $\left[\mathrm{Ag}_{21}\left\{\mathrm{~S}_{2} \mathrm{P}\left(\mathrm{O}{ }^{i} \mathrm{Pr}\right)_{2}\right\}_{12}\right]^{+}$, ${ }^{2 a}$ which can be reformulated $\left[\mathrm{Ag}_{13}\right]^{5+}\left[\mathrm{Ag}_{8}{ }_{8}\left\{\mathrm{~S}_{2} \mathrm{P}\left(\mathrm{O}^{i} \mathrm{Pr}\right)_{2}\right\}_{12}\right]^{4-}$, the outer $\left[\mathrm{Ag}_{8}{ }_{8}\left\{\mathrm{~S}_{2} \mathrm{P}\left(\mathrm{O}^{i} \mathrm{Pr}\right)_{2}\right\}_{12}\right]^{4-}$ shell being formally composed of $8 \mathrm{Ag}^{+}$cations and 12 anionic dithiophosphate ligands.

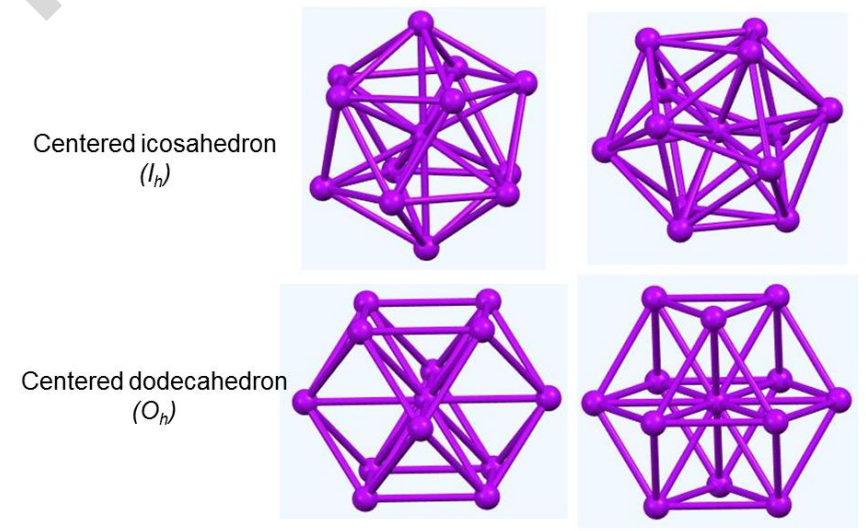

Figure 1. Two views of a centered icosahedron (top) and a centered dodecahedron (bottom). 
The closed-shell 2-electron $a_{l g}{ }^{2}\left(1 \mathrm{~S}^{2}\right)$ configuration is not forbidden for such an arrangement and actually a copper cluster with a 2-electron centered icosahedral kernel has been reported, namely $\left[\mathrm{Cu}_{25} \mathrm{H}_{22}\left(\mathrm{PPh}_{3}\right)_{12}\right]^{+}$, which can be formally reformulated $\left[\mathrm{Cu}_{13}\right]^{11+}\left[\mathrm{Cu}^{\mathrm{I}}\right.$ $\left.{ }_{12} \mathrm{H}_{22}\left(\mathrm{PPh}_{3}\right)_{12}\right]^{10-} \cdot 3$

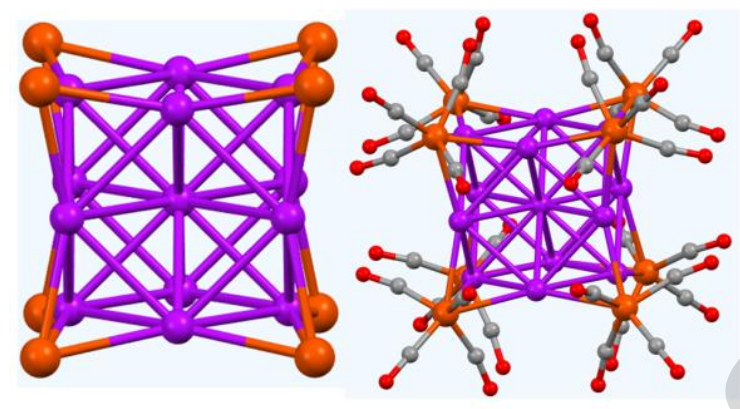

Figure 2. The octacapped cuboctahedral metal framework (left) and the full structure (right) of $\left[\mathrm{Ag}_{13}\left\{\mu_{3}-\mathrm{Fe}(\mathrm{CO})_{4}\right\}_{8}\right]^{\mathrm{n}-}(\mathrm{n}=3,4,5)$.

An alternative pseudo-spherical arrangement for a 13-atom unit is the centered cuboctahedron (Figure 1), which is slightly less compact than the centered icosahedron. To our knowledge, only three types of Group 11 clusters have been so far reported to exhibit a centered cuboctahedral kernel. One is the gold-thiolato 8-electron species $\left[\mathrm{Au}_{23}(\mathrm{SR})_{16}\right]^{-}(\mathrm{R}=$ cyclohexyl, adamantyl), ${ }^{4}$ and $\left[\mathrm{Au}_{24}(\mathrm{SR})_{16}\right]\left(\mathrm{R}=\right.$ adamantyl ${ }^{4 \mathrm{~b}}$ which can be viewed as made of a bicapped centered cuboctahedral $\left[\mathrm{Au}_{15}\right]^{7+}$ core surrounded by an outer shell composed of $16 \mathrm{SR}^{-}$ligands and 8 and 9 outer $\mathrm{Au}^{\mathrm{I}}$ centers, respectively. Another one is the recently published clusters $\left[\mathrm{Cu}_{13}\left(\mathrm{~S}_{2} \mathrm{CN}^{n} \mathrm{Bu}_{2}\right)_{6}(\mathrm{CCR})_{4}\right]^{+}\left(\mathrm{R}=\mathrm{CO}_{2} \mathrm{Me}, 3-\mathrm{FC}_{6} \mathrm{H}_{4}\right)$, which are 2-electron superatoms, with a ligand protected $\left[\mathrm{Cu}_{13}\right]^{11+}$ core. ${ }^{5}$ The third one is the $\left[\operatorname{Ag}_{13}\left\{\mu_{3-}\right.\right.$ $\left.\left.\mathrm{Fe}(\mathrm{CO})_{4}\right\}_{8}\right]^{\mathrm{n}-}(\mathrm{n}=3,4,5)$ series, of which the tri- and tetra-anionic forms have been structurally characterized by X-ray crystallography. ${ }^{6}$ In these compounds, The 8 triangular faces of the silver cuboctahedron are capped by a trigonal pyramidal $\mathrm{Fe}(\mathrm{CO})_{4}$ moiety (Figure 2). Counting the (hypothetical) jellium electrons in these anions is not straightforward. A comparison with the isostructural $\left[\mathrm{Au}_{12}\left(\mu_{12}-\mathrm{Na}\right)\left(\mu_{3}-\mathrm{Se}\right)_{8}\right]^{3-}$ cluster $^{7}$ may be instructive. In this compound, the 8 triangular faces of the Na-centered gold cuboctahedron are capped by selenide ions. Each selenide donates three electron pairs, one to each Au atom it is bonded to. Neglecting at first their interactions with the sodium cation, each of the $12 \mathrm{Au}^{\mathrm{I}}$ atoms is in an approximate linear $\mathrm{ML}_{2}$ coordination mode, receiving two electron pairs from the two 
selenides it is linked to. Thus, each $\mathrm{Au}^{\mathrm{I}}$ atom is an sp-hybridized 14-electron $\mathrm{d}^{10}$ metal center, an electron-deficient but fairly stable situation for late transition-metal centers. The nature of the interaction with the central $\mathrm{Na}^{+}$ion remains questionable, although (ionic?) interactions with the 8 selenides may be invoked. A similar localized 2-electron/2-center bonding situation can be used to understand the structure of the related empty cuboctahedral $\left[\mathrm{Cu}_{12}\left(\mu_{3}-\mathrm{S}\right)_{8}\right]^{4-}$ cluster $^{8}$ (14-electron metal centers and 8-electron sulfur centers). Using now the same approach to $\left[\mathrm{Ag}_{13}\left\{\mu_{3}-\mathrm{Fe}(\mathrm{CO})_{4}\right\}_{8}\right]^{3-}$, one can consider the $\mathrm{Fe}(\mathrm{CO})_{4}$ unit as isolobal to selenide, i.e. as a $\left[\mathrm{Fe}(\mathrm{CO})_{4}\right]^{2-}$ ligand. Indeed, with such an electron number, this trigonal pyramidal unit has three occupied (donor) frontier orbitals ( 1 of $\sigma$-type and 2 of $\pi$-type), ${ }^{9}$ similarly as $\mathrm{Se}^{2-}$. This electron partitioning is arbitrary, but allows readily realizing that the cuboctahedral $\mathrm{Ag}_{13}$ kernel is made of an $\mathrm{Ag}^{+}$ion encapsulated in a cuboctahedron made of twelve 14-electron silver centers lying in a linear coordination mode. A rather similar qualitative bonding description has been provided previously by King. ${ }^{10}$ As for the $\mathrm{Na}^{+}$cation in $\left[\operatorname{Au}_{12}\left(\mu_{12}-\right.\right.$ $\left.\mathrm{Na})\left(\mu_{3}-\mathrm{Se}\right)_{8}\right]^{3-}$, the question of the bonding between the encapsulated $\mathrm{Ag}^{+}$ion and its host cage is still to be solved. Going now to the reduced form $\left[\operatorname{Ag}_{13}\left\{\mu_{3}-\mathrm{Fe}(\mathrm{CO})_{4}\right\}_{8}\right]^{5-}$, one can anticipate that the added electron pair will occupy an orbital which is a bonding combination of the $5 \mathrm{~s} \mathrm{AO}$ of the encapsulated atom and 5p AOs of the cuboctahedron silver atoms. Indeed, each of these linearly coordinated 14-electron centers has two $5 \mathrm{p}_{\pi}$ vacant orbitals, one radial and one tangential with respect to the pseudo-spherical symmetry, the former one being nicely suited for overlaping with the central $5 \mathrm{~s}$ AO. Such a qualitative picture is consistent with a 2electron $\left(1 \mathrm{~S}^{2}\right)$ superatom configuration. It is also consistent with EPR measurement data on the tetra-anion $\left[\mathrm{Ag}_{13}\left\{\mu_{3}-\mathrm{Fe}(\mathrm{CO})_{4}\right\}_{8}\right]^{4-}$, 6a which suggests substantial localization of the unpaired electron on the central atom. Previous calculations are also consistent with a pentaanion HOMO having a significant contribution from the $5 \mathrm{~s} \mathrm{AO}$ of the central atom. ${ }^{6 a, 11}$ In the followings, we rationalize by DFT calculations the electronic structure and the bonding within the $\left[\mathrm{Ag}_{13}\left\{\mu_{3}-\mathrm{Fe}(\mathrm{CO})_{4}\right\}_{8}\right]^{\mathrm{n}-}(\mathrm{n}=3,4,5)$ series and other related hypothetical species, with emphasis on the interaction between the encapsulated atom and its host cage. The optical properties of the tri- and penta-anion are also investigated, as well as the stability of the $\mathrm{Ag}_{13}$ cuboctahedral arrangement with respect to the icosahedral one for the 8-electron superatom count. 


\section{Computational details}

Geometry optimizations at the density functional theory (DFT) level were performed with the Gaussian 09 package. ${ }^{12}$ The BP86 functional ${ }^{13}$ was used together with the general triple- $\xi$ polarized Def2-TZVP basis set from EMSL basis set exchange library, with an all-electron basis set on silver. ${ }^{14}$ Analytical calculations of the vibrational frequencies were performed on all the optimized geometries to verify that these structures are local minima on the potential energy surface. Wiberg indices and natural orbital populations were computed with the NBO 5.0 program, ${ }^{15}$ but because of computational limits, the Wiberg indices were calculated on the BP86/Def2-TZVP-optimized geometries using the more contracted LANL2DZ basis set, ${ }^{15}$ augmented with Ahlrichs polarization functions on all atoms. ${ }^{16 e}$. The UV-visible transitions were calculated on the BP86/Def2-TZVP-optimized geometries by means of time-dependent DFT (TDDFT) calculations, ${ }^{17}$ using the CAM-B3LYP ${ }^{18}$ functional and the same Def2-TZVP basis set. Only singlet-singlet, i.e. spin-allowed, transitions have been computed. The UVvisible spectra were simulated from the computed TDDFT transitions and their oscillator strengths by using the SWizard program, ${ }^{19}$ each transition being associated with a Gaussian function of half-height width equal to $1500 \mathrm{~cm}^{-1}$. In order to identify potential artifacts on the TDDFT results due to the substantial anionic charges of the clusters, TDDFT calculations have been also carried out with the two clusters embedded in a cube of point charges of value +0.5 u.a. This procedure, which allows preserving the cluster $O_{h}$ symmetry reduces the isolated trianion charge to +1 and that of the penta-anion to -1 . The point charges were placed on the $C_{3}$ axes at a distance of $3 \AA$ from the carbonyl oxygens. Despite of a significant effect on the Kohn-Sham MO energies, the computed UV-vis absorption spectra simulated from these calculations are about the same as those computed for the free anions. The corresponding simulated UV-vis spectra are given as supplementary information (Table S1).

The compositions of the molecular orbitals were calculated using the AOMix program. ${ }^{20}$

In order to get a more detailed picture of the bonding within some of the computed compounds, fragment interaction analyses have been performed with the help of the ADF2013 program. ${ }^{21}$ Indeed, the ADF code enables analyzing the Kohn-Sham molecular orbitals on the basis of fragment orbitals and provides a useful decomposition of the bonding energy between fragments, according to the Morokuma-Ziegler scheme, ${ }^{22}$ which allows comparisons of bond strengths and nature within series of compounds. ADF calculations were carried out as single-points on the Gaussian-optimized structures with the BP86 functional and an STO all-electron TZ2P basis set. ${ }^{23}$ 


\section{Results and discussion}

Naked closed-shell superatoms. As mentioned above, in a Group $11 \mathrm{M}_{13}$ superatom, each metal atom can be considered in first approximation as participating to the bonding only with one $\mathrm{s}$ valence orbital and consequently the $\mathrm{M}_{13}$ superatom can meet stable closed-shell situation for only two jellium electron counts, namely $2\left(1 \mathrm{~S}^{2}\right)$ and $8\left(1 \mathrm{~S}^{2} 1 \mathrm{P}^{6}\right)$. Within the simple Hückel model, the more compact centered icosahedron ( $I_{h}$ symmetry) is found to be more stable than the centered dodecahedron $\left(O_{h}\right.$ symmetry) for both electron counts. For 2 electrons the stabilization energy is computed to be $13.54 \beta$ and $12.00 \beta$ for the former and latter, respectively ( $a_{1 g}{ }^{2}$ configuration). For 8 electrons, the stabilization energy is $26.96 \beta$ and $24.00 \beta$, respectively $\left(a_{1 g}{ }^{2} t_{1 u}{ }^{6}\right.$ configuration in both symmetry groups). DFT calculations (see above) on an 8-electron bare cluster $\left[\mathrm{Ag}_{13}\right]^{5+}$ found the icosahedral structure more stable than the cuboctahedral one by $4.4 \mathrm{kcal} / \mathrm{mol}$. Moreover, vibrational frequency calculations indicated that the latter is not a minimum. Releasing the $O_{h}$ symmetry constraint on the cuboctahedral arrangement leads to a converged icosahedral geometry. Thus the cuboctahedral arrangement is not a stable structure for the naked $\left[\mathrm{Ag}_{13}\right]^{5+}$ cluster. In the case of the 2-electron system, it was of course not possible, using DFT, to optimize a bound geometry for the naked $\left[\mathrm{Ag}_{13}\right]^{11+}$ core, due to its very large positive charge. Results based on single point calculations on both structures were found unreliable due to their extreme sensibility with respect to the $\mathrm{Ag}-\mathrm{Ag}$ distances.

The empty $\left[\mathrm{Ag}_{12}\left\{\mu_{3}-\mathrm{S}\right\}_{8}\right]^{4-}$ cuboctahedral model. To the best of our knowledge, this cluster has not been characterized, but it can be considered as the silver analogue of the well-known $\left[\mathrm{Cu}_{12}\left\{\mu_{3}-\mathrm{S}\right\}_{8}\right]^{4-8}$. The major metric data of its optimized geometry are provided in Table 1 , together with some computed electronic data. The calculated results are fully consistent with the qualitative description of a localized 2-electron/2-center bonding mode (see introduction), with linearly coordinated $\mathrm{Ag}^{\mathrm{I}}$ 14-electron centers (see the almost $\mathrm{d}^{10}$ silver NAO configuration in Table 1). The 2 x 12 metal-ligand bonding electron pairs are provided by the 8 sulfide ligands which are therefore regular $\mathrm{sp}^{3}$-hybridized 8-electrons main-group centers. The stability of the whole assembly is secured by a large HOMO-LUMO gap of $2.85 \mathrm{eV}$, separating the $e_{u} \mathrm{HOMO}$, a sulfur lone pair combination, from the $a_{1 g}$ LUMO which is largely silver localized ( $64 \%$, of which $47 \%$ of $5 \mathrm{~s} / 5 \mathrm{p}$ contribution). Finally, the question of a possible delocalization associated with some Ag...Ag bonding may be raised. The corresponding bond distance (3.26 $\AA$ ) and Wiberg index (0.036) are consistent with very weak covalent bonding, as usually found when argentophilic interactions are present. ${ }^{24}$ 
The empty $\left[\mathrm{Ag}_{12}\left\{\mu_{3}-\mathrm{Fe}(\mathrm{CO})_{4}\right\}_{8}\right]^{4-}$ cuboctahedral model. Replacing the $\mathrm{S}^{2-}$ ligands in $\left[\mathrm{Cu}_{12}\left\{\mu_{3}-\mathrm{S}\right\}_{8}\right]^{4-}$ by trigonal pyramidal $\left[\mathrm{Fe}(\mathrm{CO})_{4}\right]^{2-}$ isolobal ${ }^{9}$ moieties does not change that much the bonding within the cluster (Table 1), as exemplified by the silver NAO configuration which remains almost unchanged upon substitution. The Ag...Ag separation is slightly shortened and the corresponding Wiberg index slightly larger. Thus, the $O_{h}$ empty clusters $\left[\mathrm{Cu}_{12}\left\{\mu_{3}-\mathrm{S}\right\}_{8}\right]^{4-}$ and $\left[\mathrm{Ag}_{12}\left\{\mu_{3}-\mathrm{Fe}(\mathrm{CO})_{4}\right\}_{8}\right]^{4-}$ have closely related electronic structures, the iron carbonyl units in the latter playing the role of regular triply-bridging ligands. The only significant difference between the two clusters being the smaller (but still significant) HOMO-LUMO gap in the latter, due to the appearance of occupied iron $3 \mathrm{~d}$ non-bonding levels which are of higher energy than sulfur lone pairs in the latter.

The $\left[\mathrm{Ag}_{13}\left\{\mu_{3}-\mathrm{Fe}(\mathrm{CO})_{4}\right\}_{8}\right]^{3-c l u s t e r}$. The optimized $\mathrm{O}_{h}$ trianion is found to be slightly more expanded than its experimental structure ${ }^{6 \mathrm{~b}}$ (see Table 1), likely because of its negative charge which is not counterbalanced by any cationic environment in the computed model. The Morokuma-Ziegler decomposition of the bonding energy ${ }^{21}$ between the $\left[\operatorname{Ag}_{12}\left\{\mu_{3}-\right.\right.$ $\left.\left.\mathrm{Fe}(\mathrm{CO})_{4}\right\}_{8}\right]^{4-}$ cage and its encapsulated $\mathrm{Ag}^{+}$host (Table 2) was performed by using the ADF program at the BP86/TZP level (see Computational details) of the beforehand optimized geometry. The total bonding energy between the two fragments is negative (stabilizing). Among the three components of this bonding energy, the Pauli repulsion is, by nature, positive. On the other hand, the two other components (electrostatic and orbital interactions) are stabilizing. In particular, it is noteworthy that the electrostatic interaction is not dominated, as one might expect a priori, by coulombic repulsions between the encapsulated and outer formally $\mathrm{Ag}^{\mathrm{I}}$ metal centers. Thus, despite the lack of "jellium" (5s) electrons, $\operatorname{Ag}^{\mathrm{I}}$ (center)... $\operatorname{Ag}^{\mathrm{I}}$ (cage) covalent bonding interactions, in which $5 \mathrm{~d}$ orbitals are involved, are present in $\left[\mathrm{Ag}_{13}\left\{\mu_{3}-\mathrm{Fe}(\mathrm{CO})_{4}\right\}_{8}\right]^{3-}$, in agreement with its chemical stability. 


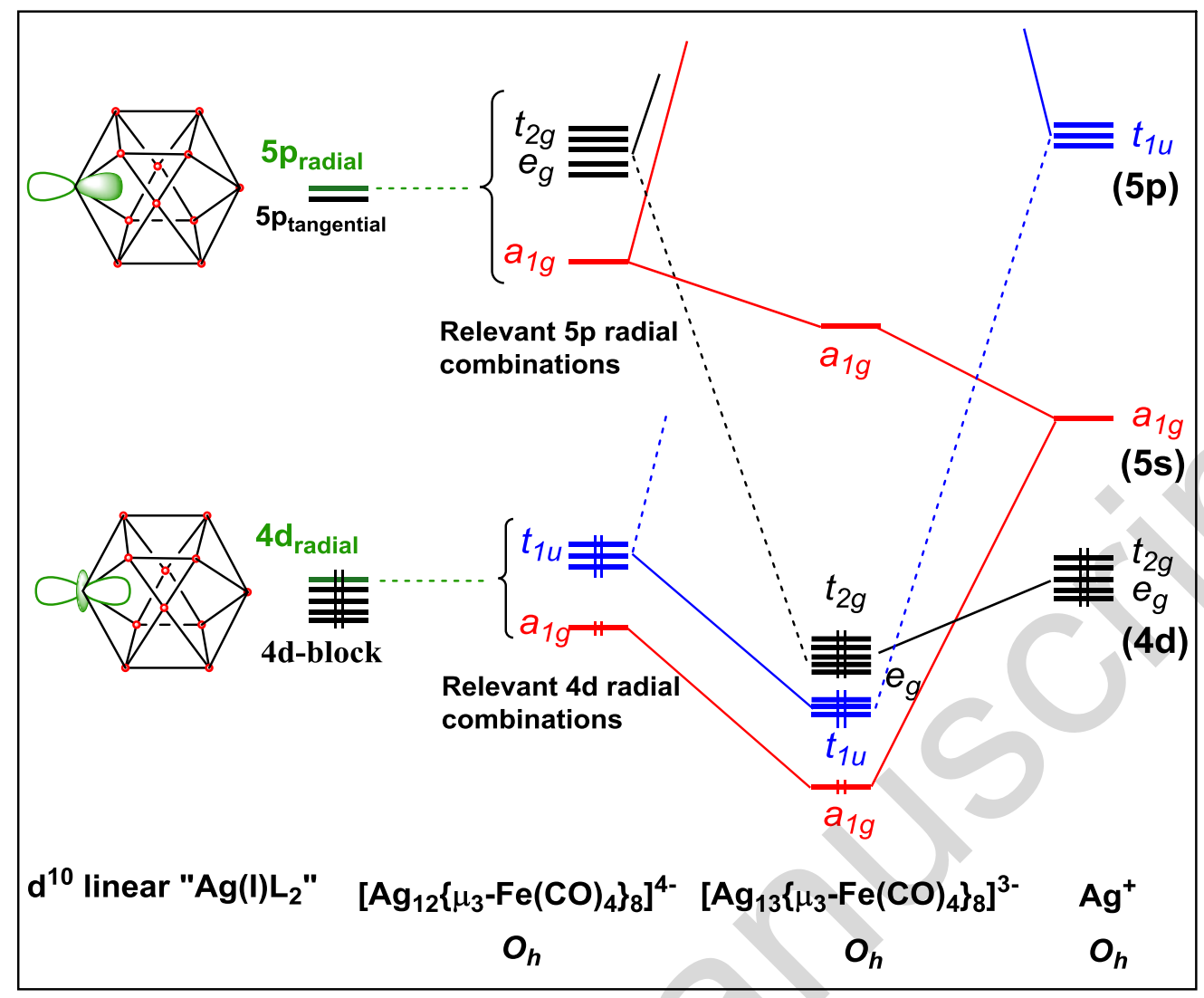

Figure 3. Simplified frontier MO diagram illustrating the interaction between the $\left[\operatorname{Ag}_{12}\left\{\mu_{3}-\right.\right.$ $\left.\left.\mathrm{Fe}(\mathrm{CO})_{4}\right\}_{8}\right]^{4-}$ cage and its encapsulated $\mathrm{Ag}^{+}$host in $\left[\mathrm{Ag}_{13}\left\{\mu_{3}-\mathrm{Fe}(\mathrm{CO})_{4}\right\}_{8}\right]^{3-}$. Only the $4 \mathrm{~d}$ and $5 \mathrm{p}$ radial combinations of $\left[\mathrm{Ag}_{12}\left\{\mu_{3}-\mathrm{Fe}(\mathrm{CO})_{4}\right\}_{8}\right]^{4-}$ playing a significant role in the interaction are considered. The individual MO diagram of one of the twelve linearly coordinated $\mathrm{Ag}^{\mathrm{I}}$ centers is recalled on the left side.

The orbital interaction energy is decomposed into its irreducible representation components in Table 2 and a simplified frontier MO interaction diagram taken out of this fragment analysis is sketched in Figure 3. The corresponding computed Kohn-Sham MO diagram is shown in Figure 4. The major contributions to the orbital interaction energy come from its $a_{l g}$ and $t_{l u}$ components (Table 2). They result from donation of occupied 4d-type combinations of the $\left(\mathrm{Ag}^{\mathrm{I}}\right)_{12}$ cuboctahedron into the vacant $5 \mathrm{~s}\left(a_{1 g}\right)$ and $5 \mathrm{p}\left(t_{1 u}\right)$ orbitals of the encapsulated $\mathrm{Ag}^{\mathrm{I}}$ atom. Significantly weaker but non negligible $e_{g}$ and $t_{2 \mathrm{~g}}$ contributions arise from backdonation from the occupied $4 \mathrm{~d}$ orbitals of the encapsulated $\mathrm{Ag}^{\mathrm{I}}$ into vacant combinations of the radial $5 p$ AOs of the $\left(\mathrm{Ag}^{\mathrm{I}}\right)_{13}$ cuboctahedron. As a result, the $\mathrm{Ag}$ (center) NAO configuration exhibit significant $5 \mathrm{~s}$ and $5 \mathrm{p}$ population (Table 1 ), leading to a slightly negative atomic charge (-0.02), whereas the $\mathrm{Ag}$ (outer) one (+0.40) is slightly higher than in the empty $\left[\mathrm{Ag}_{12}\left\{\mu_{3}-\mathrm{Fe}(\mathrm{CO})_{4}\right\}_{8}\right]^{4-}$ relative $(+0.38)$. As already pointed up by Longoni and coworkers in their original publication, ${ }^{6 a}$ The $1 a_{1 g}$ LUMO of $\left[\mathrm{Ag}_{13}\left\{\mu_{3}-\mathrm{Fe}(\mathrm{CO})_{4}\right\}_{8}\right]^{3-}$, which lies in the middle of an energy gap (Figure 4), results from a 3-orbital interaction pattern (Figure 1). It is 
composed of the 5s $\mathrm{AO}$ of $\mathrm{Ag}$ (center), mixed in an antibonding way with an $a_{1 g}$ combination of the occupied $4 \mathrm{~d} \mathrm{Ag}$ (outer) orbitals, and mixed in a bonding way with the $a_{1 g}$ LUMO of the empty $\left[\mathrm{Ag}_{12}\left\{\mu_{3}-\mathrm{Fe}(\mathrm{CO})_{4}\right\}_{8}\right]^{4-}$ cage, the latter being mainly a bonding combination of the radial 5p AOs of the $\left(\mathrm{Ag}^{\mathrm{I}}\right)_{12}$ cuboctahedron (neglecting the $\mathrm{Fe}(\mathrm{CO})_{4}$ participation). The LUMO of $\left[\mathrm{Ag}_{13}\left\{\mu_{3}-\mathrm{Fe}(\mathrm{CO})_{4}\right\}_{8}\right]^{3-}$ has a $10 \%$ contribution from $5 \mathrm{~s}$ of $\mathrm{Ag}($ center) and $31 \%$ from the $\mathrm{Ag}$ (outer atoms) of which $20 \%$ are $5 \mathrm{p}$ and $10 \%$ are $4 \mathrm{~d}$ participations. It is concluded that the nature of the bonding with the ligand shell is crucial in determining the cuboctahedral arrangement, as well as the bonding between the cage and the encapsulated atom. Finally, it is noteworthy that the number of occupied MOs shown in Figure 3 for $\left[\operatorname{Ag}_{12}\left\{\mu_{3}-\mathrm{Fe}(\mathrm{CO})_{4}\right\}_{8}\right]^{4-}(4$ radial MOs) and $\left[\operatorname{Ag}_{13}\left\{\mu_{3}-\mathrm{Fe}(\mathrm{CO})_{4}\right\}_{8}\right]^{3-}(4$ radial +5 central $=9)$ can be related to the number of electron bonding pairs characterizing empty and centered "electron-deficient" icosahedral transition-metal clusters within a scheme developed by Teo et al. ${ }^{25}$

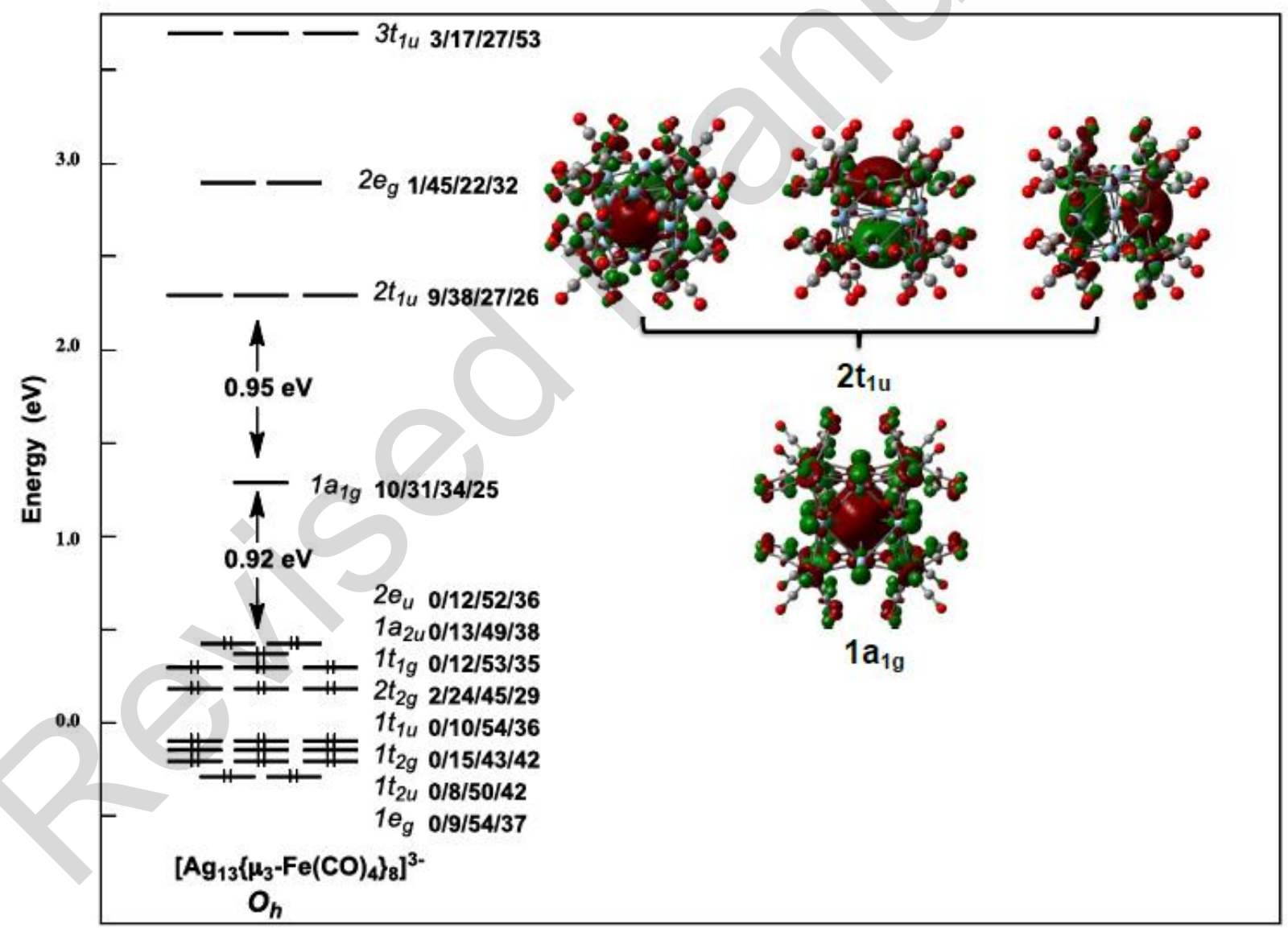

Figure 4. Computed Kohn-Sham MO diagram of $\left[\operatorname{Ag}_{13}\left\{\mu_{3}-\mathrm{Fe}(\mathrm{CO})_{4}\right\}_{8}\right]^{3-}$. The MO localization (in \%) is given as follows: $\mathrm{Ag}$ (center) $/ \mathrm{Ag}_{12} / \mathrm{Fe}_{8} / \mathrm{CO}$ ligands. 
Table 1. Relevant computed data for $\left[\mathrm{Ag}_{13}\left(\mu_{3}-\mathrm{E}\right)_{8}\right]^{\mathrm{n}-}\left(\mathrm{E}=\right.$ vacancy, $\mathrm{S}, \mathrm{Fe}(\mathrm{CO})_{4} ; \mathrm{n}=3$, 5). Averaged experimental values ${ }^{6 \mathrm{~b}}$ are given into brackets.

\begin{tabular}{|c|c|c|c|c|c|}
\hline Coumpound & {$\left[\mathrm{Ag}_{12} \mathrm{~S}_{8}\right]^{4-}$} & {$\left[\operatorname{Ag}_{12}\left\{\mathrm{Fe}(\mathrm{CO})_{4}\right\}\right]^{4-}$} & {$\left[\mathrm{Ag}_{12}(\mathrm{Na})\left\{\mathrm{Fe}(\mathrm{CO})_{4}\right\}_{8}\right]^{3-}$} & {$\left[\operatorname{Ag} 13\left\{\mathrm{Fe}(\mathrm{CO})_{4}\right\}_{8}\right]^{3-}$} & {$\left[\operatorname{Ag}_{13}\left\{\mathrm{Fe}(\mathrm{CO})_{4}\right\}\right]^{5-}$} \\
\hline $\mathrm{d}\left[\mathrm{Ag} / \mathrm{Na}-\mathrm{Ag}^{*}\right] / \AA$ & 3.255 & 3.054 & 3.130 & 3.057 [2.929] & 3.031 \\
\hline $\mathrm{d}[\mathrm{Ag}($ outer)-E$] / \AA$ & 2.458 & 2.803 & 2.780 & $2.788[2.712]$ & 2.886 \\
\hline $\mathrm{d}[\mathrm{Ag} / \mathrm{Na}$ (center)-E] $/ \AA$ & - & - & 4.669 & $4.829[4.697]$ & 4.999 \\
\hline $\mathrm{WI}[\mathrm{Ag} / \mathrm{Na}(\text { center})-\mathrm{Ag}(\text { outer })]^{* *}$ & - & - & 0.057 & 0.085 & 0.066 \\
\hline WI[Ag(outer)-Ag(outer)] & 0.036 & 0.073 & 0.058 & 0.054 & 0.060 \\
\hline $\mathrm{Na} / \mathrm{Ag}\left(\right.$ center) configuration ${ }^{* * *}$ & - & - & $3 \mathrm{~s}^{0.43} 3 \mathrm{p}^{0.16} 3 \mathrm{~d}^{0.01}$ & $4 d^{9.95} 5 s^{0.95} 5 p^{0.12}$ & $4 d^{9.93} 5 s^{1.33} 5 p^{0.10}$ \\
\hline $\operatorname{Ag}($ outer $)$ configuration & $4 d^{9.88} 5 s^{0.68} 5 p^{0.03}$ & $4 d^{9.89} 5 s^{0.68} 5 p^{0.01}$ & $4 d^{9.88} 5 s^{0.70} 5 p^{0.02}$ & $4 d^{9.88} 5 s^{0.67} 5 p^{0.02}$ & $4 d^{9.89} 5 s^{0.66} 5 p^{0.02}$ \\
\hline HOMO-LUMO gap /eV & 2.85 & 1.56 & 1.40 & 0.92 & 0.94 \\
\hline
\end{tabular}

(*) In a regular centered cuboctahedron of $O_{h}$ symmetry, $\mathrm{Ag} / \mathrm{Na}$ (center)- $\mathrm{Ag}($ outer $)=\mathrm{Ag}($ outer $)-\mathrm{Ag}($ outer $)$.

(**) $\mathrm{WI}=$ Wiberg index

$(* * *)$ Natural atomic orbital (NAO) population analysis. 
Table 2. Decomposition of the bonding energy between the $\left[\operatorname{Ag}_{12}\left\{\mu_{3}-\mathrm{Fe}(\mathrm{CO})_{4}\right\}_{8}\right]^{4-}$ and $\mathrm{X}^{+/-}$ fragments in $\left[\mathrm{Ag}_{12}\left(\mu_{12}-\mathrm{X}\right)\left\{\mu_{3}-\mathrm{Fe}(\mathrm{CO})_{4}\right\}_{8}\right]^{3-/ 5-} .(\mathrm{X}=\mathrm{Na}, \mathrm{Ag})$. All energies are in $\mathrm{eV}$.

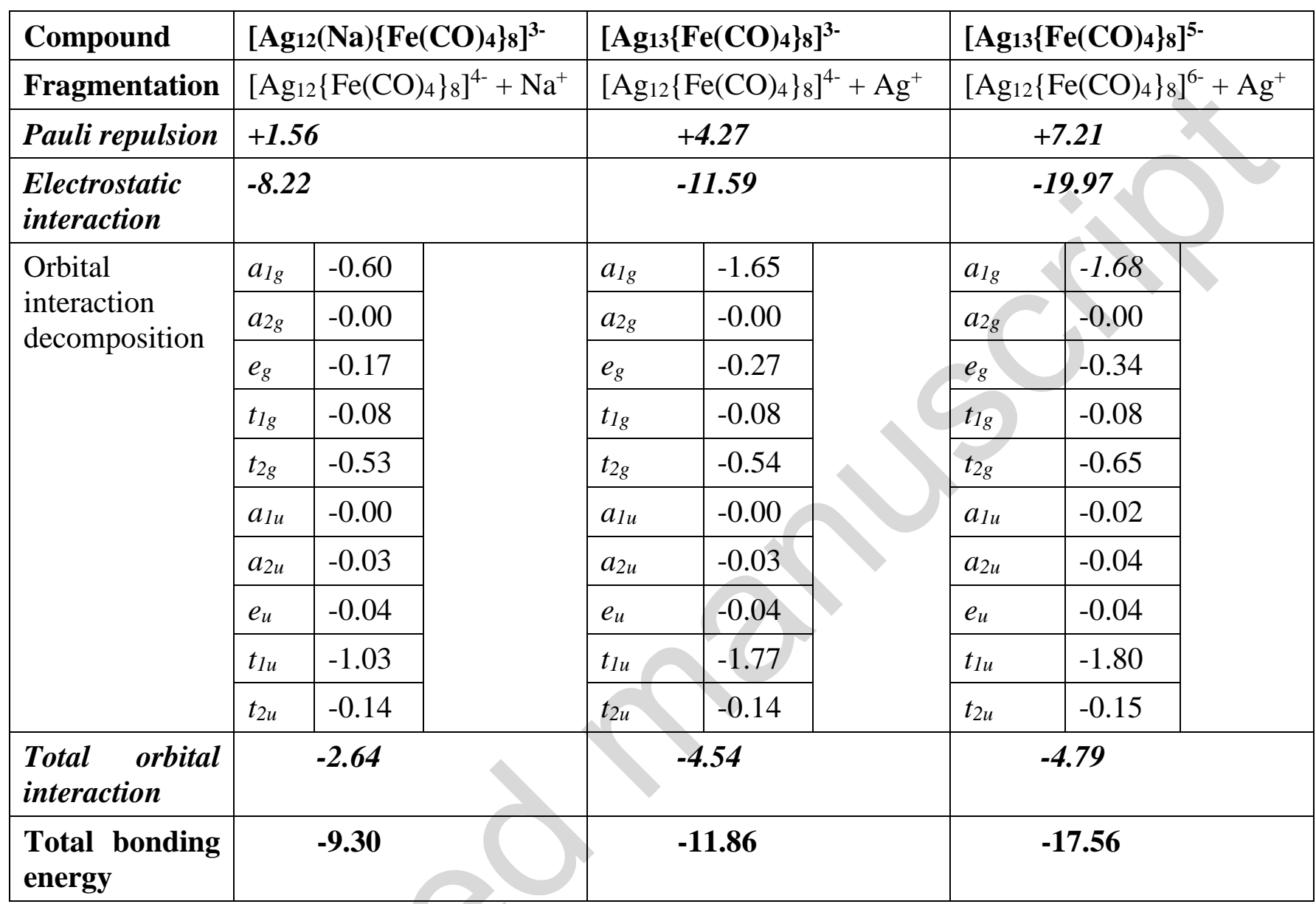


The $\left[\mathrm{Ag}_{13}\left\{\mu_{3}-\mathrm{Fe}(\mathrm{CO})_{4}\right\}_{8}\right]^{5-}$ cluster. Going from the tri- to the penta-anion corresponds to the occupation of the $a_{1 g}$ orbital described above (The $1 a_{1 g}$ LUMO in Figure 4). It induces some shortening of the Ag-Ag distances and lengthening of the Ag-Fe ones, an effect which was experimentally observed upon reduction of the trianion. ${ }^{6}$ Whereas in the tri-anion, the $a_{1 g}$ LUMO of the empty $\left[\mathrm{Ag}_{12}\left\{\mu_{3}-\mathrm{Fe}(\mathrm{CO})_{4}\right\}_{8}\right]^{4-}$ is unsignificantly involved in the interaction with the encapsulated $\mathrm{Ag}^{\mathrm{I}}$ fragment because it does not mix with occupied level of the latter, with two more electrons it participates in a bonding way to the penta-anion HOMO and becomes the dominant cuboctahedron orbital involved in the $a_{1 g}$ component of the orbital interaction energy. Indeed, the occupation of this fragment orbital varies from 0.01 in the tri-anion to 1.37 in the penta-anion, whereas in the same time that of the $\mathrm{Ag}$ (center) $5 \mathrm{~s} \mathrm{AO}$ varies from 0.63 to 1.02 . This $a_{1 g}$ 3-orbital system allows maintaining the corresponding orbital interaction energy almost constant whether it is occupied by two or four electrons (see Table 2). On the same time, the other symmetry components are little affected by the reduction of the trianion. Thus, from the nature of its HOMO and neglecting its partial localization on the $\mathrm{Fe}(\mathrm{CO})_{4}$ groups, $\left[\mathrm{Ag}_{13}\left\{\mu_{3}-\mathrm{Fe}(\mathrm{CO})_{4}\right\}_{8}\right]^{5-}$ can be described as a 2-electron superatom, the $1 \mathrm{~S}$ occupied orbital of which being the result of a bonding combination between the $5 \mathrm{~s}$ AO of $\mathrm{Ag}$ (center) and the radial 5p AOs of the $\mathrm{Ag}$ (outer) atoms ( $1 a_{1 g}$ in Figure 4). On the other hand, the vacant $2 t_{1}$ level can be identified as the next $1 \mathrm{P}$ jellium shell. Finally, one should mention that, applying the electron counting scheme for related icosahedral clusters developed by Teo et $a .^{25}\left[\mathrm{Ag}_{13}\left\{\mu_{3}-\mathrm{Fe}(\mathrm{CO})_{4}\right\}_{8}\right]^{5-}$ should be considered as a 20 -electron species.

The $\left[\mathrm{Ag}_{12}(\mathrm{Na})\left\{\mu_{3}-\mathrm{Fe}(\mathrm{CO})_{4}\right\}_{8}\right]^{3-} \quad$ cuboctahedral model. The existence of the likely isoelectronic $\left[\mathrm{Au}_{12}\left(\mu_{12}-\mathrm{Na}\right)\left(\mu_{3}-\mathrm{Se}\right)_{8}\right]^{3-}$ and $\left[\mathrm{Ag}_{13}\left\{\mu_{3}-\mathrm{Fe}(\mathrm{CO})_{4}\right\}_{8}\right]^{3-}$ clusters ${ }^{7,} 8$ leads us to calculate the sodium analog of $\left[\operatorname{Ag}_{13}\left\{\mu_{3}-\mathrm{Fe}(\mathrm{CO})_{4}\right\}_{8}\right]^{3-}$, i.e., the $\left[\operatorname{Ag}_{12}(\mathrm{Na})\left\{\mu_{3}-\mathrm{Fe}(\mathrm{CO})_{4}\right\}_{8}\right]^{3-}$ model, the most relevant computed data of which are given in Tables 1 and 2. Interestingly, both electrostatic and orbital components of the bonding energy between $\mathrm{Na}^{+}$and its host cage are weaker than that of its $\mathrm{Ag}^{+}$homologue. On the other hand the Pauli component is less repulsive so that the total bonding energy is still significant $(-9.30 \mathrm{eV}, v s .-11.86 \mathrm{eV}$ in the case of $\mathrm{Ag}^{+}$). Unsurprisingly, the major contributions of the orbital bonding energy component come from the interaction of the vacant $3 \mathrm{~s}\left(a_{l g}\right)$ and $3 \mathrm{p}\left(t_{l u}\right)$ AOs of $\mathrm{Na}^{+}$with occupied 4d-type combinations of the $\left(\mathrm{Ag}^{\mathrm{I}}\right)_{13}$ cuboctahedron of the same symmetry. Although significant, these contributions are not as important as in $\left[\mathrm{Ag}_{13}\left\{\mu_{3}-\mathrm{Fe}(\mathrm{CO})_{4}\right\}_{8}\right]^{3-}$. Interestingly, the $e_{g}$ and $t_{2 g}$ secondary contributions have similar values as in $\left[\operatorname{Ag}_{13}\left\{\mu_{3}-\mathrm{Fe}(\mathrm{CO})_{4}\right\}_{8}\right]^{3-}$. 
Whereas in the latter they involve the occupied $4 \mathrm{~d} A O s$ of the encapsulated $\mathrm{Ag}^{+}$, in the former they involve the vacant $3 \mathrm{~d}$ polarization $\mathrm{AOs}$ of $\mathrm{Na}^{+}$which stabilize occupied 4d-type combinations of the $\left(\mathrm{Ag}^{\mathrm{I}}\right)_{13}$ cuboctahedron of the same symmetry.

Optical properties of the $\left[\mathrm{Ag}_{13}\left\{\mu_{3}-\mathrm{Fe}(\mathrm{CO})_{4}\right\}_{8}\right]^{3-/ 5-}$ species. As mentioned above, when going from the tri- to the penta-anion, one occupies an orbital situated in the middle of a significant energy gap. This is expected to induce some differences in the UV-vis absorption between both species. Their simulated spectra obtained from TDDFT calculations (see Computational details) are shown in Figure 5. In the case of the tri-anion, the strong band at $\sim 410 \mathrm{~nm}$ corresponds to an iron to silver charge transfer and is associated with a combination of two major transitions. One of them involves a low-lying $t_{l u}$ level and the $1 a_{1 g}$ LUMO. The other one is the $2 t_{2 g} \rightarrow 2 t_{1 u}$ transition (see Figure 4). This band is also present in the simulated penta-anion spectrum, slightly shifted to lower energy $(\sim 420 \mathrm{~nm})$ and is now mainly of $2 t_{2 g}$ $\rightarrow 2 t_{l u}$ character. Interestingly, a new band appears in the penta-anion spectrum at $934 \mathrm{~nm}$. It is due to the $1 a_{1 g}(\mathrm{HOMO}) \rightarrow 2 t_{1 u}(\mathrm{LUMO})$ transition and has no significant electron-transfer character.

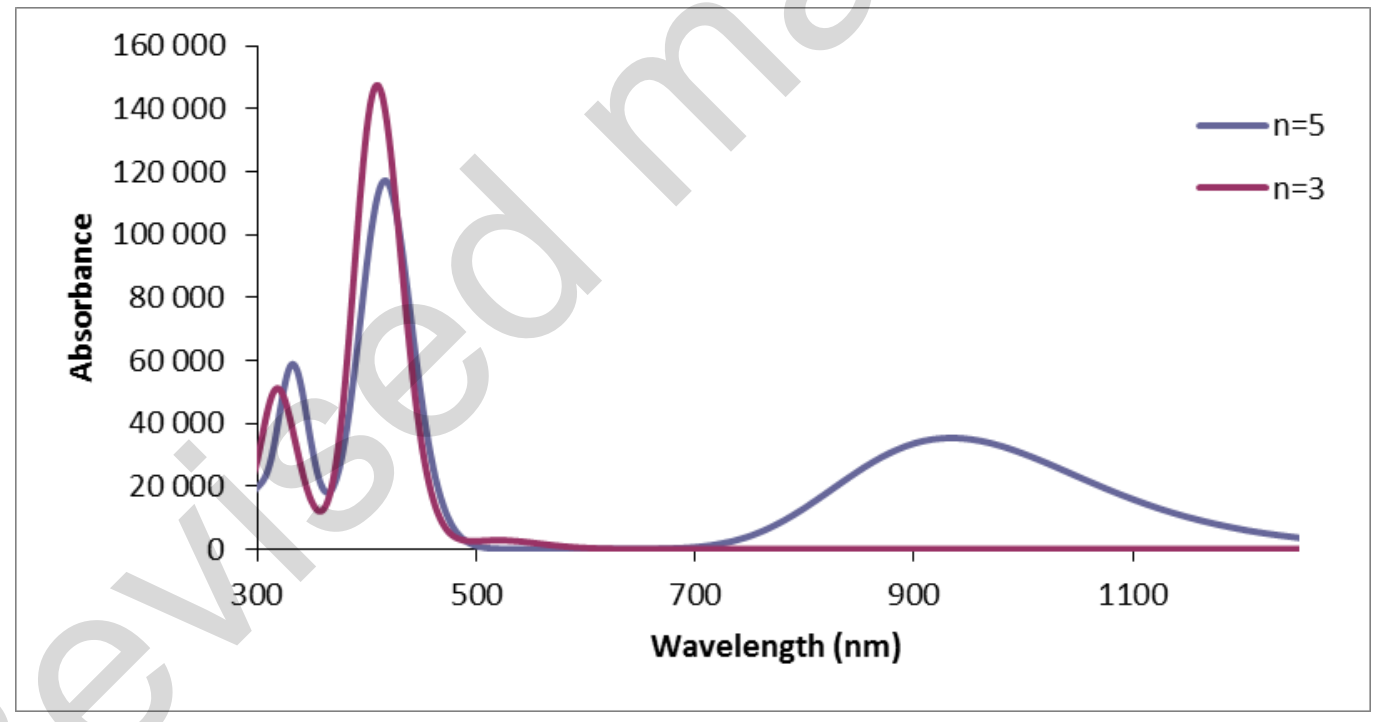

Figure 5. TDDFT-simulated UV-vis absorption spectra of $\left[\operatorname{Ag}_{13}\left\{\mu_{3}-\mathrm{Fe}(\mathrm{CO})_{4}\right\}_{8}\right]^{\mathrm{n}-}(\mathrm{n}=3,5)$.

The appearance of this band in the near IR region prompted us to investigate the possibility of phosphorescence associated with the same transition. The emission wavelength computed from the optimized triplet state is $1632 \mathrm{~nm}$. As a matter of fact, a similar value is obtained for the tri-anion $(1644 \mathrm{~nm})$. At our level of theory and modelization (isolated poly- 
anions in vacuum), these values should be considered only at a qualitative level, but from these results one can tentatively anticipate optical activities in the near-IR region.

The $\left[\mathbf{A g}_{23}(\mathbf{S H})_{16}\right]^{-}$model. This silver cluster was chosen as a model for $\left[\mathrm{Au}_{23}(\mathrm{SR})_{16}\right]^{-}(\mathrm{R}=$ $\left.\mathrm{C}_{6} \mathrm{H}_{11}\right)$ species, ${ }^{4}$ which can be described as a distorted bicapped centered cuboctahedral $\left[\mathrm{Au}_{15}\right]^{7+} 8$-electron core protected by a passivating $\left[\mathrm{Au}_{8}{ }_{8}(\mathrm{SR})_{16}\right]^{8-}$ outer shell (see above). ${ }^{4} \mathrm{~A}$ related $\left[\mathrm{Au}_{24}(\mathrm{SR})_{16}\right]$, structure, which has an additional outer $\mathrm{Au}^{\mathrm{I}}$ center, is also known. ${ }^{4 \mathrm{~b}}$ Despite its "magic" 8-electron count, $\left[\mathrm{Au}_{23}(\mathrm{SR})_{16}\right]$ was originally described as a nonsuperatom species, probably owing to its distorted cuboctahedral arrangement. ${ }^{\text {ta }}$ On the other hand, in a recent comprehensive analysis of bonding in gold clusters, Mingos described this cluster as conforming to the regular jellium model, ${ }^{26}$ thanks to the capping principle ${ }^{27}$ applied to the capping of two opposite square faces of the cuboctahedron in the $\left[\mathrm{Au}_{15}\right]^{7+}$ core. ${ }^{4}$

The computed $\left[\mathrm{Ag}_{23}(\mathrm{SH})_{16}\right]^{-}$model $\left(C_{i}\right.$ symmetry) exhibits a similar structure as its real gold relative. The computed HOMO-LUMO gap is $1.05 \mathrm{eV}$, a value which compares well with that found for $\left[\mathrm{Ag}_{13}\left\{\mathrm{Fe}(\mathrm{CO})_{4}\right\}_{8}\right]^{5-}$ at the same level of theory $(0.94 \mathrm{eV})$. As found in the case of $\left[\operatorname{Ag}_{13}\left\{\mathrm{Fe}(\mathrm{CO})_{4}\right\}_{8}\right]^{5-}$, the computed NAO charge of the central atom in $\left[\operatorname{Ag}_{23}(\mathrm{SH})_{16}\right]^{-}$is negative (-0.32), with the $4 \mathrm{~d}^{9.89} 5 \mathrm{~s}^{1.19} 5 \mathrm{p}^{0.23}$ electron configuration. As expected from previous work $^{2}$ the formally $\mathrm{Ag}^{\mathrm{I}}$ outer atoms have a positive charge of $\sim+0.6$. The 14 non-central atoms of the $\left[\mathrm{Ag}_{15}\right]^{+7}$ bicapped dodecahedral core have lower charges, ranging between +0.15 and +0.32 , except for the two of them which are the farthest away from the cuboctahedron center $(+0.61)$ and which appear to behave as $\mathrm{Ag}^{\mathrm{I}}$ centers, being significantly connected only to two sulfur atoms. Nevertheless, an examination of the Kohn-Sham MOs associated with the 8 core electrons is consistent with the qualitative description of Mingos for $\left[\mathrm{Au}_{23}(\mathrm{SR})_{16}\right]^{-26}$ i.e., an approximate $a_{1 g}{ }^{2} a_{2 u}{ }^{2} e_{u}{ }^{4}$ jellium electron configuration in the $D_{4 h}$ pseudo-symmetry of the bicapped centered dodecahedral core. Thus, we suggest considering $\left[\operatorname{Ag}_{23}(\mathrm{SR})_{16}\right]^{-}$as a regular 8-electron superatom, despite its fairly non-spherical core shape.

\section{Final remarks}

Whereas the naked icosahedral $\left[\mathrm{Ag}_{13}\right]^{5+} 8$-electron superatom is found to be only slightly more stable than in the dodecahedral configuration, the energy difference between both structures would likely to be larger if the cluster was a ligated (neutral) 8-electron species. This should be also the case in real systems where $\left[\mathrm{Ag}_{13}\right]^{5+}$ is surrounded by an anionic passivating shell of ligands. Indeed, the nuclear repulsions between the positively charged atoms in $\left[\mathrm{Ag}_{13}\right]^{5+}$ are expected to conflict more strongly with the covalent bonding 
interaction in the more compact icosahedral configuration. On the other hand, the strong covalent interactions between the superatomic core and its surrounding ligands are also to be considered, and the nature and size of this outer shell can induce a preference for the dodecahedral configuration as already suggested by other authors in the case of $\left[\mathrm{Au}_{23}(\mathrm{SR})_{16}\right]^{-}$ and $\left[\mathrm{Au}_{24}(\mathrm{SR})_{16}\right]$ species. $^{4 \mathrm{~b}}$ Such a ligand effect is likely to be even more efficient for a 2 electron superatom such as in $\left[\operatorname{Ag}_{13}\left\{\mu_{3}-\mathrm{Fe}(\mathrm{CO})_{4}\right\}_{8}\right]^{5-}$ and, a fortiori, in the 0-electron $\left[\mathrm{Ag}_{13}\left\{\mu_{3}-\mathrm{Fe}(\mathrm{CO})_{4}\right\}_{8}\right]^{3-}$. Conical units such as $\mathrm{Fe}(\mathrm{CO})_{4}$, are particularly suited for capping triangular faces. In addition steric repulsions between ligands are minimized in the cuboctahedral case. The number of metal-ligand bonds in which the twelve metals constituting the core polyhedron are involved is also crucial, for it determines the nature and strength of the interaction with the encapsulated atom. In the case of the $\left[\operatorname{Ag}_{13}\left\{\mu_{3^{-}}\right.\right.$ $\left.\left.\mathrm{Fe}(\mathrm{CO})_{4}\right\}_{8}\right]^{3-/ 5-}$ system, the peculiar electron-deficient character of the outer 14-electron silver centers allows significant covalent interaction with the encapsulated atom, irrespectively from the cluster 0- or 2-electron count.

In any event, we have tested the possibility for stabilizing a jellium 8-electron count with the $\mathrm{Ag}_{13}$ centered cuboctahedral arrangement. The computed model was $\left[\mathrm{Ag}_{13}\left\{\mu_{3}-\mathrm{Cl}\right\}_{8}\right]^{3-}$ , in which the eight triangular faces of the $\left[\mathrm{Ag}_{13}\right]^{5+}$ core are capped by chloride ligands. The geometry optimized under the $O_{h}$ symmetry constraint corresponds to the expected $1 \mathrm{~S}^{2} 1 \mathrm{P}^{6}$ jellium configuration, but with a rather small HOMO-LUMO $(0.91 \mathrm{eV})$. Overall, this $O_{h}$ structure is not an energy minimum (largest imaginary frequency: $33 \mathrm{i} \mathrm{cm}^{-1}$ ). Lowering the symmetry leads to a non-cuboctahedral arrangement. This result suggests that 8-electron cuboctahedral $\mathrm{Ag}_{13}$ species are unlikely to exist.

Finally, it should be noted that ligated $\operatorname{Ag}^{\mathrm{I}}{ }_{12}$ cuboctahedral cages encapsulating halides are known. ${ }^{28}$ Thus, the possibility for such cages to encapsulate formally $\mathrm{Ag}^{-}$anions, thus making a 2-electron $\left[\mathrm{Ag}_{13}\right]^{11+}$ superatom is not to be excluded. Conversely, one might consider replacing the encapsulated $\mathrm{Ag}^{-}$anion in $\left[\mathrm{Ag}_{13}\left\{\mathrm{Fe}(\mathrm{CO})_{4}\right\}_{8}\right]^{5-}$ by an halide. Consistently, the optimized structures of $\left[\mathrm{Ag}_{12}(\mathrm{X})\left\{\mathrm{Fe}(\mathrm{CO})_{4}\right\}_{8}\right]^{5-}(\mathrm{X}=\mathrm{Cl}, \mathrm{Br}, \mathrm{I})$ appear to be viable $^{29}$ in the same octacapped dodecahedral $O_{h}$ configuration as $\left[\mathrm{Ag}_{13}\left\{\mathrm{Fe}(\mathrm{CO})_{4}\right\}_{8}\right]^{5-}$, with substantial HOMO-LUMO gaps of 2.20, 2.26 and $2.37 \mathrm{eV}$, respectively and optimized Ag-X $=\mathrm{Ag}-\mathrm{Ag}$ distances are 3.17, 3.22 and $3.29 \AA$ for $\mathrm{X}=\mathrm{Cl}, \mathrm{Br}$ and I, respectively.

Acknowledgements The GENCI-CINES and GENCI-IDRISS French national computer centers are acknowledged for computational resources (grant x2016-087367). 


\section{References}

1. (a) Zeng, C.; Jin. R. Gold nanoclusters: size-controlled synthesis and crystal structures. Struct. Bond. 2014, 161, 87-115. (b) Jin, R.; Zeng, C.; Zhou, M.; Chen, Y. Chem. Rev. Atomically Precise Colloidal Metal Nanoclusters and Nanoparticles: Fundamentals and Opportunities. Chem. Rev., 2016, 116, 10346-10413. (c) Häkkinen, H. Atomic and electronic structure of gold clusters: understanding flakes, cages and superatoms from simple concepts. Chem. Soc. Rev. 2008, 37, 1847-1859. (d) Teo, B. K.; Yang, S.-Y. Jelliumatic shell model. J. Clust Sci. 2015, 26, 1923-1941.

2. (a) Dhayal, R. S.; Liao, J.-H.; Liu, Y. C.; Chiang, M.-H.; Kahlal, S.; Saillard, J.-Y.; Liu, C. W. $\left[\mathrm{Ag}_{21}\left\{\mathrm{~S}_{2} \mathrm{P}\left(\mathrm{O}^{\mathrm{i}} \mathrm{Pr}\right)_{2}\right\}_{12}\right]^{+}$: An eight-electron superatom. Angew. Chem. Int. Ed. Engl. 2015, 54, 3702-3706. (b) Dhayal, R. S.; Lin, Y.-R.; Liao, J.-H.; Chen, Y.-J.; Liu, Y.-C.; Chiang, M.-H.; Kahlal, S.; Saillard, J.-Y.; Liu, C. W. $\left[\operatorname{Ag}_{20}\left\{\mathrm{~S}_{2} \mathrm{P}(\mathrm{OR})_{2}\right\}_{12}\right]$ : a superatom complex with a chiral metallic core and high potential for isomerism. Chem. Eur. J. 2016, 22, 9943-9947.

3. Nguyen, T.-A. D. ; Jones, Z. R.; Goldsmith, B. R.; Buratto, W. R.; Wu, G.; Scott, S. L.; Hayton, T. W. A $\mathrm{Cu}_{25}$ Nanocluster with partial $\mathrm{Cu}(0)$ character. J. Am. Chem. Soc. 2015, 137, 13319-13324.

4. (a) Das, A.; Li, T.; Nobusada, K.; Zeng, C.; Rosi, N. L.; Jin, R. Nonsuperatomic $\left[\mathrm{Au}_{23}\left(\mathrm{SC}_{6} \mathrm{H}_{11}\right)_{16}\right]^{-}$nanocluster featuring bipyramidal $\mathrm{Au}_{15}$ kernel and trimeric $\mathrm{Au}_{3}(\mathrm{SR})_{4}$ motif. J. Am. Chem. Soc. 2013, 135, 18264-18267. (b) Crasto, D.; Barcaro, G.; Stener, M.; Sementa, L.; Fortunelli, A.; Das, A. J. Au $24(\mathrm{SAdm})_{16}$ nanomolecules: X-ray crystal structure, theoretical analysis, adaptability of adamantane ligands to form $\mathrm{Au}_{23}(\mathrm{SAdm})_{16}$ and $\mathrm{Au}_{25}(\mathrm{SAdm})_{16}$, and its relation to $\mathrm{Au}_{25}(\mathrm{SR})_{18}$. Am. Chem. Soc. 2014, 136, 14933-14940.

5. Chakrahari, K. K.; Liao, J.-H. ; Kahlal, S.; Liu, Y.-C.; Chiang M.-H.; Saillard, J.-Y.; Liu, C. W. $\left[\mathrm{Cu}_{13}\left(\mathrm{~S}_{2} \mathrm{CN}^{n} \mathrm{Bu}_{2}\right)_{6}(\text { acetylide })_{4}\right]^{+}$: A two-electron superatom. Angew. Chem. Int. Ed. 2016, 55, 14704-14708.

6. (a) Albano, V. G.; Grossi, L.; Longoni, G.; Monari, M.; Mulley, S.; Sironi, A. Synthesis and characterization of the paramagnetic $\left[\mathrm{Ag}_{13} \mathrm{Fe}_{8}(\mathrm{CO})_{32}\right]^{4-}$ tetraanion: a cuboctahedral $\mathrm{Ag}_{13}$ cluster stabilized by $\mathrm{Fe}(\mathrm{CO})_{4}$ groups behaving as 4-electron donors. J. Am. Chem. Soc. 1992, 114, 5708 - 5713. (b) Albano, V. G.; Calderoni, F.; Iapalucci, M. C.; Longoni, G.; Monari, M.; Zanello, P. Synthesis, chemical, and electrochemical characterization of the $\left[\operatorname{Ag}_{13}\left\{\mu_{3}-\mathrm{Fe}(\mathrm{CO})_{4}\right\}_{8}\right]^{\mathrm{n}-}(\mathrm{n}=3,4,5)$ cluster 
anions: $x$-ray structural determination of $\left[\mathrm{N}\left(\mathrm{PPh}_{3}\right)_{2}\right]_{3}\left[\mathrm{Ag}_{12}\left(\mu_{12}-\mathrm{Ag}\right)\left\{\mu_{3}-\mathrm{Fe}(\mathrm{CO})_{4}\right\}_{8}\right] . J$. Cluster Sci. 1995, 6, 107-123.

7. Huang, S.-P.; Kanatzidis, M. G. Synthesis and structure of the cluster $\left[\mathrm{NaAu}_{12} \mathrm{Se}_{8}\right]^{3-}$ : An inorganic cryptand complex. Angew. Chem. Int. Ed. Engl. 1992, 31, 787-789.

8. (a) Betz, P.; Krebs, B.; Henkel, G. $\left[\mathrm{Cu}_{12} \mathrm{~S}_{8}\right]^{4-}$ : A closed binary Copper(I) sulfide cage with cuboctahedral metal and cubic Sulfur arrangements. Angew. Chem. Int. Ed. Engl. 1984, 23, 311-312. (b) Yang, L.; Wang, Z.; Powell, D. R.; Houser, R. P. A $\left[\mathrm{Cu}_{16} \mathrm{~S}_{10}\right]^{4-}$ cluster containing $\mu_{3-}$ and $\mu_{4}$-sulfido ligands. Dalton Trans. 2009, 44394441. (c) Zhao, X.-W. ; Qian, L.-W. ; Su, H.-C. ; Mo, C.-J. ; Que, C.-J.; Zhu, Q.-Y. ; Dai, J. Co-assembled T4-Cu $\mathrm{In}_{16} \mathrm{~S}_{35}$ and cubic $\mathrm{Cu}_{12} \mathrm{~S}_{8}$ clusters: A crystal precursor for near-infrared absorption material. Cryst.Growth Des. 2015, 15, 5749-5753.

9. Albright; T. A.; Burdett, J. K.; Whangbo, M.-H. Orbital Interactions in Chemistry; Wiley: Hoboken, N. J., 2013.

10. King, R. B. Metal cluster topology 16. Macropolygons and macropolyhedra in coinage metal iron carbonyl cluster anions and related compounds. Inorg. Chim. Acta 1994, 227, 207-209.

11. Albert, K.; Neymann, K. M.; Pacchioni, G.; Rösch, N. Electronic and geometric structure of bimetallic clusters: density functional calculations on $\left[\mathrm{M}_{4}\left\{\mathrm{Fe}(\mathrm{CO})_{4}\right\}_{4}\right]^{4-}$ $(\mathrm{M}=\mathrm{Cu}, \mathrm{Ag}, \mathrm{Au})$ and $\left[\mathrm{Ag}_{13}\left\{\mathrm{Fe}(\mathrm{CO})_{4}\right\}_{8}\right]^{\mathrm{n}-}(\mathrm{n}=0-5)$. Inorg. Chem. 1996, 35, 73707376.

12. Gaussian 09, Revision E.01, Frisch, M. J.; Trucks, G. W.; Schlegel, H. B.; Scuseria, G. E.; Robb, M. A.; Cheeseman, J. R.; Scalmani, G.; Barone, V.; Mennucci, B.; Petersson, G. A.; Nakatsuji, H.; Caricato, M.; Li, X.; Hratchian, H. P.; Izmaylov, A. F.; Bloino, J.; Zheng, G.; Sonnenberg, J. L.; Hada, M.; Ehara, M.; Toyota, K.; Fukuda, R.; Hasegawa, J.; Ishida, M.; Nakajima, T.; Honda, Y.; Kitao, O.; Nakai, H.; Vreven, T.; Montgomery, J. A., Jr.; Peralta, J. E.; Ogliaro, F.; Bearpark, M.; Heyd, J. J.; Brothers, E.; Kudin, K. N.; Staroverov, V. N.; Kobayashi, R.; Normand, J.; Raghavachari, K.; Rendell, A.; Burant, J. C.; Iyengar, S. S.; Tomasi, J.; Cossi, M.; Rega, N.; Millam, J. M.; Klene, M.; Knox, J. E.; Cross, J. B.; Bakken, V.; Adamo, C.; Jaramillo, J.; Gomperts, R.; Stratmann, R. E.; Yazyev, O.; Austin, A. J.; Cammi, R.; Pomelli, C.; Ochterski, J. W.; Martin, R. L.; Morokuma, K.; Zakrzewski, V. G.; Voth, G. A.; Salvador, P.; Dannenberg, J. J.; Dapprich, S.; Daniels, A. D.; Farkas, Ö.; 
Foresman, J. B.; Ortiz, J. V.; Cioslowski, J.; Fox, D. J. Gaussian, Inc., Wallingford CT, 2009.

13. a) Becke, A. D. Density-functional exchange-energy approximation with correct asymptotic behavior. Phys. Rev. A, 1988, 38, 3098-3100; b) Perdew, J. P. Densityfunctional approximation for the correlation energy of the onhomogeneous electron gas. Phys. Rev. B, 1986, 33, 8822-8824.

14. Weigend, F.; Ahlrichs, R. Phys. Chem. Chem. Phys. Balanced basis sets of split valence, triple zeta valence and quadruple zeta valence quality for $\mathrm{H}$ to $\mathrm{Rn}$ : Design and assessment of accuracy. 2005, 7, 3297-3305.

15. Glendening, E. D.; Badenhoop, J. K.; Reed, A. E.; Carpenter, J. E.; Bohmann, J. A.; Morales, C. M.; Weinhold, F. NBO 5.0; Theoretical Chemistry Institute, University of Wisconsin: Madison, WI, 2001, http://www.chem.wisc.edu/ nbo5.

16. a) Dunning, Jr., T. H.; Hay, P. J. in Methods of Electronic Structure Theory, (Eds. Schaeffer, H. J.), Plenum Press: New York, 1977; b) Hay, P. J.; Wadt, W. R. J. Chem. Phys. 1985, 82, 270-283; c) Hay, P. J.; Wadt, W. R. Ab initio effective core potentials for molecular calculations. Potentials for the transition metal atoms Sc to Hg. J. Chem. Phys. 1985, 82, 284-298; d) Hay, P. J.; Wadt, W. R. Ab initio effective core potentials for molecular calculations. Potentials for $\mathrm{K}$ to $\mathrm{Au}$ including the outermost core orbitals. J. Chem. Phys. 1985, 82, 299-310; e) Schaefer, A.; Horn, H.; Ahlrichs, R. Fully optimized contracted Gaussian basis sets for atoms Li to Kr. J. Chem. Phys. 1992, 97, 2571-2577.

17. Burke, K; Gross, E. K. U. A guided tour of Time-Dependent Density Functional Theory, in Density Functionals: Theory and Applications, (Lecture Notes in Physics), Vol. 500; D. Joubert Ed.; Springer, 1998.

18. Yanai, T.; Tew, D.; Handy, N. A new hybrid exchange-correlation functional using the Coulomb-attenuating method (CAM-B3LYP). Chem. Phys. Lett.2004, 393, 51-57.

19. Gorelsky, S. I. SWizard program, revision 4.5, http://www.sg-chem.net/

20. Gorelsky, S. I. AOMix program, http://www.sg-chem.net/

21. (a) te Velde, G.; Bickelhaupt, F. M.; van Gisbergen, S. J. A.; Fonseca Guerra, C.; Baerends, E. J.; Snijders J. G.; Ziegler, Chemistry with ADF. J. Comput. Chem. 2001, 22, 931-967. (b) ADF2013, SCM, Theoretical Chemistry, Vrije Universiteit, Amsterdam, The Netherlands, http://www.scm.com. 
22. (a) Ziegler, T.; Rauk, A. Theoretical study of the ethylene-metal bond in complexes between $\mathrm{Cu}^{+}, \mathrm{Ag}^{+}, \mathrm{Au}^{+}, \mathrm{Pt}^{0}$, or $\mathrm{Pt}^{2+}$ and ethylene, based on the Hartree-Fock-Slater transition-state method. Inorg. Chem. 1979, 18, 1558-1565. (b) Bickelhaupt F. M.; Baerends, E. J. In: Rev. Comput. Chem.; K. B. Lipkowitz and D. B. Boyd, Eds.; Wiley, New York, 2000, Vol. 15, p.1-86.

23. van Lenthe E.; Baerends, E. J. Optimized Slater-type basis sets for the elements 1-118, J. Comput. Chem. 2003, 24, 1142-1156.

24. Liu, C. W.; Liao, P.-K.; Feng, C.-S.; Saillard, J.-Y.; Kahlal, S.; Wang, J.-C. An eleven-vertex deltahedron with hexacapped trigonal bipyramidal geometry. Chem. Commun. 2011, 47, 5831-5833.

25. Teo, B. K.; Zhang, H.; Kean, Y. ; Dang, H. ; Shi, X. Binary icosahedral clusters: atom and electron counting rules. J. Chem. Phys. 1993, 99, 2929-2941.

26. Mingos, D. M. P. Structural and bonding patterns in gold clusters. Dalton Trans. 2015, $44,6680-6695$.

27. (a) Thomas, K. M.; Mason, R.; Mingos, D. M. P. Stereochemistry of octadecacarbonylhexaosmium(0). Novel hexanuclear complex based on a bicapped tetrahedron of metal atoms. J. Am. Chem. Soc. 1973, 95, 3802-3804. (b) Mingos, D. M. P.; Forsyth, M. I. Molecular-orbital calculations on transition-metal cluster compounds containing six metal atoms. Dalton Trans., 1977, 610-616.

28. Liao, J.-H.; Latouche, C.; Li, B.; Kahlal, S.; Saillard, J.-Y.; Liu, C. W. A Twelvecoordinated iodide in a cuboctahedral silver(I) skeleton. Inorg. Chem. 2014, 53, 22602267.

29. Hoffmann, R.; von Ragué Schleyer, P.; Schaefer III, H. F. Predicting molecules-More realism, please. Angew. Chem. Int. Ed. Engl. 2008, 47, 7164-7167. 


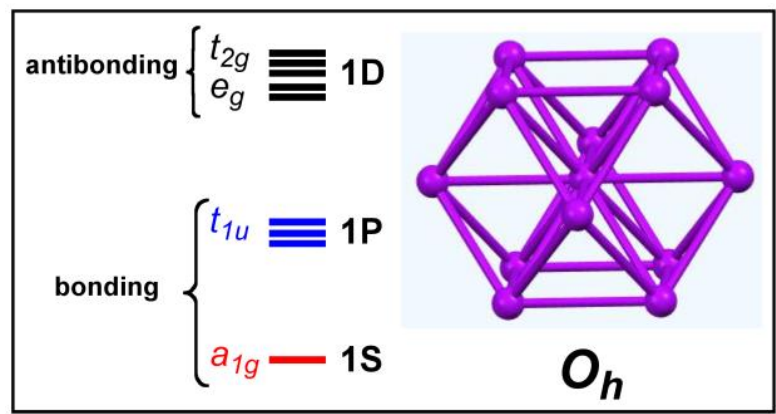

\section{Synopsis}

Depending on its ligand and/or additional metal coverage, the $\operatorname{Ag}_{13}$ centered cuboctahedron can reach closed-shell stability for 0,2 or 8 silver electrons. This architecture is particularly favored when octa-capped by main-group or organometallic ligand and housing 0 or 2 electrons (with expected luminescence properties), whereas it is unlikely for 8 electrons. Calculations predict stability for related halogenide-centered species. 